\title{
Comparison of fixed and mobile-bearing total knee arthroplasty in terms of patellofemoral pain and function: a prospective, randomised, controlled trial
}

\author{
P. Z. Feczko ${ }^{1 *}$ D, L. M. Jutten ${ }^{1}$, M. J. van Steyn², P. Deckers ${ }^{3}$, P. J. Emans ${ }^{1}$ and J. J. Arts ${ }^{1}$
}

\begin{abstract}
Background: Despite growing evidence in the literature, there is still a lack of consensus regarding the use of the mobile-bearing (MB) design total knee arthroplasty (TKA).

Methods: In a prospective, comparative, randomised, single centre trial, 106 patients with end-stage osteoarthritis of the knee were randomised to either an MB or fixed-bearing (FB) group to receive posterior stabilised (PS)-TKA using a standard medial parapatellar approach and patellar resurfacing with follow-up (FU) for 5 years. The primary outcome was anterior knee pain (AKP) during the chair rise test and the stair climb test 5 years after surgery. The secondary outcome was the ability to rise from a chair and to climb stairs, range of motion (ROM), Knee Society Score (KSS), RAND-36 scores and radiological analysis of the patellar tilt.
\end{abstract}

Results: No statistically significant difference was found between the two groups at 5 years FU in terms of median AKP during the chair rise test and the stair climb test ( $p=0.5$ and $p=0.8$, respectively). There was no significant difference in any of the other secondary outcome parameters between the groups at 5 years FU.

Conclusion: A mobile-bearing TKA does not decrease AKP compared to fixed bearings.

Trial registration number: ClinicalTrials.gov NCT02892838.

Level of evidence: ॥

Keywords: Total knee arthroplasty, Anterior knee pain, Mobile bearing, Fixed bearing

\section{Background}

Total knee arthroplasty (TKA) is a successful surgical treatment for osteoarthritis of the knee [1-3]. This intervention results in excellent long-term survivorship [4-7] and marked improvement in functional capacity and quality of life for the patients [8]. However anterior knee pain (AKP) is present in 4 to $40 \%$ of all cases [9-11] independently of patellar resurfacing, restricting the patients in climbing stairs, rising from a chair, cycling, or, in worst case scenarios, walking normally. The causes of AKP are multifactorial and can be divided into non-modifiable and

\footnotetext{
* Correspondence: p.feczko@mumc.nl

${ }^{1}$ Department of Orthopaedic Surgery, CAPHRI Research School, Maastricht

University Medical Centre, P. Debyelaan 25, 6229 HX Maastricht, the

Netherlands

Full list of author information is available at the end of the article
}

modifiable factors $[12,13]$. Non-modifiable factors are young age, female gender, ethnicity and low pain threshold [14-17]. Modifiable factors can be patient related, like anxiety, depression, pain processing problems [18, 19], muscle imbalance and dynamic valgus during gate [12]. A wide range of non-patient related, modifiable factors are published in the literature to explain and treat AKP after TKA [12-17]. Van Jonbergen [20] found inflammatory changes in the Hoffa and local peripatellar synovitis. Van Jonbergen and coworkers reported a positive effect on AKP by resection of the Hoffa and peripatellar synovectomy. Patellar clunk syndrome [21-23] and the degree of wear of the patellar cartilage [24] were also linked with AKP. There is also growing evidence that prosthetic design features such as the morphology of the anterior flange of the femoral component, gender femoral component, single or 
multi radius design, and post-cam mechanism can have an influence on AKP $[14,15,25-29]$. The literature mostly reports on surgery-related factors after TKA. The application of circumpatellar electrocautery does not lessen the incidence of AKP [30, 31]. Resurfacing the patella also remains controversial [32-34]. According to Heergaard [35] TKA leads in nearly all cases to different patellar tracking and increased patellofemoral contact pressures. In contrast to the healthy knee in which conformity between the articular surfaces is optimal, the patellofemoral contact zones are significantly reduced after TKA [35]. Restoration of the standard patellar thickness and central positioning of the patella may minimise the contact forces [36, 37]. There is good experimental and clinical evidence that poor femoral or tibial rotational alignment can adversely affect patellar tracking and kinematics [35, 38-40]. The question is how to achieve optimal tibio-femoral and patellofemoral kinematics.

The mobile-bearing $(\mathrm{MB})$ design TKA was introduced in the United States in 1980 first with the meniscal bearing concept, followed by the rotating platform design. The MB-TKA was developed to reduce polyethylene contact stresses and wear resulting in a lower rate of aseptic loosening. The other design goal was to create a selfaligning nature for the implants to provide an improved, more natural prosthetic knee joint and alignment with better functional results [41-46]. The MB design TKA was theoretically a revolutionary and attractive concept, however the clinical benefit is still controversial. Most meta-analyses could not show any benefit for the use of the MB-TKA [42, 47-50] in terms of clinical scores, loosening, ROM, pain, complications, quality of life, patient satisfaction and revision rate. There is no data in the meta-analyses for MB- versus fixed-bearing (FB) TKA in terms of AKP. Theoretically the MB design offers the potential advantage of self-correction of a rotational mismatch between the tibia and femur providing an optimization of patellofemoral mechanics and a potential reduction in AKP [51, 52] Most studies examine the kinematics of the patellofemoral joint in MB-TKA. Stiehl et al. [53] suggested that the MB design may reduce the patellofemoral maltracking resulting from the femoral component malposition conditions. Colwell [54] stated that the MB design can compensate for the malrotation of the femoral component on a limited basis. Sawaguchi [55] found in an intraoperative study where the medial shift and lateral tilt of the patella were significantly smaller in MB-TKA compared with FB-TKA. Lower patellofemoral contact stresses were found in MB-TKA compared with FB-TKA, however both designs had increased contact stress compared with native knees [56]. The New-Zealand Joint Registry study found a higher rate of revision for secondary resurfacing of the patella in the FB-TKA group [57].
The aim of the study was to collect more clinical data for AKP in MB- vs. FB-TKA patients. A prospective, comparative, randomised, single centre, trial including 106 patients was performed to compare mobile-bearing (MB) and fixed-bearing (FB) posterior stabilised (PS) TKA with patella resurfacing at 5 years follow-up (FU).

The primary outcome was anterior knee pain during the chair rise test and the stair climb test 5 years after surgery. The secondary outcome was the ability to rise from a chair and to climb stairs, range of motion (ROM), Knee Society Score (KSS), RAND-36 scores and radiological analysis of the patellar tilt 5 years after surgery.

The null hypothesis was that patients in the MB-TKA group do not exhibit less AKP during rising from a chair or climbing stairs.

The alternative hypothesis (H1) was that patients in the MB-TKA group do exhibit less AKP during rising from a chair or climbing stairs.

\section{Method \\ Trial design}

A prospective, comparative, randomised, single centre trial that included 106 patients was performed to compare MB and FB PS-TKA with patella resurfacing at 5 years follow-up (FU). Patients with end-stage osteoarthritis of the knee were randomised to either an $\mathrm{MB}$ or FB group to receive PS-TKA using a standard medial parapatellar approach.

\section{Ethics, participant selection and consent}

Ethical approval was obtained from the local ethical committee of Maastricht (METC 08-055), as part of the research program, "Should my knee rotate? A randomised controlled trial to compare fixed and mobile-bearing total knee arthroplasty using the Scorpio PS SuperFlex and Scorpio + PS Mobile Bearing knee systems". Patients were randomised (random permuted blocks of changing size) in either the $\mathrm{MB}$ or the $\mathrm{FB}$ group. The randomization process was computer generated using SPSS software. The randomization scheme ensured that during the enrolment period the ratio of the number of cases in the two groups remained constant. A written informed consent was obtained from all participants. All data was collected at the Department of Orthopaedics of Maastricht University Medical Centre. All patients and the researcher, who collected the data, was blinded. The surgeons were not blinded (see also author's contribution).

Trial Registration Number: ClinicalTrials.gov NCT02892838 Retrospectively registered (2 Sep 2016).

\section{Inclusion and exclusion criteria}

Inclusion criteria included patients between 21 and 80 years of age who had an established diagnosis of knee osteoarthritis or post-traumatic arthritis requiring primary 
total knee replacement. Exclusion criteria included mediolateral instability greater than 10 degrees, active inflammation or infection of the knee, and patients with diagnosed systemic disease (such as bone diseases, immunologically suppressed conditions, neuromuscular deficits, Complex Regional Pain Syndrome (CRPS) that would have affected the overall outcome of the study. In addition, patients were excluded if they we unable to receive a patella component (e.g., old patella fracture, too thin patella, etc.).

\section{Interventions (operative procedure)}

The aim of the operation was to achieve neutral coronal limb alignment $\pm 2^{\circ}$ and a stable knee defined as having a maximum of $0-3 \mathrm{~mm}$ laxity of the collateral ligaments [58].

All knee surgeries were performed by two surgeons. A medial parapatellar approach was applied in all cases using a tourniquet. The rotational position of the femoral component was determined by using the Whiteside's line and the transepicondylar line (TEA) [59, 60]. The rotational position of the tibial tray was determined by using the medial one third of the tibial tubercle $[61,62]$. The tibial slope was corrected to 0 degrees. With both techniques, after determining proper prosthetic size, the collateral ligaments were balanced as required based on ligament tension assessed during functional testing of the prosthetic implant [63]. Patients younger than 70 years of age received cementless femoral and tibial components, while patients older than 70 years of age received cemented implants using Simplex-P (Stryker Howmedica Osteonics, Allendale, NJ USA) containing antibiotics. Cemented patellar surface implantation was performed in every case. In each case, a Scorpio (Stryker Howmedica Osteonics, Allendale, NJ USA) PS implant was used with fixed- or mobile-bearing inserts.

\section{Outcome measurements}

Clinical outcomes were assessed by a blinded independent examiner. All clinical outcome parameters were assessed preoperatively and postoperatively at 6 weeks, 3 and 6 months, 1,2 and 5 years.

The primary outcome was AKP during the chair raise test and the stair climb test measured on a visual analogue scale (VAS) $[64,65] 5$ years after surgery. The secondary outcome was the ability to rise from a chair and to climb stairs, range of motion (ROM), Knee Society Score (KSS), RAND-36 scores and radiological analysis of the patellar tilt 5 years after surgery.

The chair rise test was assessed according to the Jones' description [66]. The initial sitting position during the chair rise test was standardised. The patients were sitting on an adjustable chair with the hip and knee in $90^{\circ}$ of flexion. The patients had to stand up from the chair without using their arms. The test was repeated five times and patients were asked to report pain and location of the pain. It was noted whether the patients were able to rise (yes or no) and the VAS was used to measure AKP.

In order to standardise the movement during stair climbing, the same stairs were used by each individual patient. The patients had to walk up and down 10 steps with alternating legs without using the handrail. It was noted whether the patients were able to rise (yes or no) and VAS was used to measure AKP. ROM was measured during physical examination using a goniometer according to the technique described by Norkin [67]. Intratester and inter-tester reliability was described by Brosseau [68], the reproducibility by Lenssen [69]. Knee Society Scores [70] and RAND-36 scores [71, 72] were also measured.

\section{Radiological evaluations}

Standard plain radiographs with Merchant 30/60/90 views were performed preoperatively and postoperatively at 6 weeks, 3 and 6 months, 1,2 and 5 years. The position of the patella was measured from the Merchant view producing an angle between a line through the most prominent parts of the femur and a line through the backside of the patellar component (cement-component interface) [73]. Mean and median values were used for further analyses.

\section{Statistics and sample size analysis}

Descriptive statistics were used to summarise the data. Differences between 'fixed' and 'mobile' at 5 years were tested using Mann-Whitney U tests for continuous variables as normal distribution could not be assumed and chi-squared tests or Fisher's Exact tests for categorical variables. Statistical analyses were performed using $\mathrm{R}$ version 3.3.1 (R Foundation, Vienna, Austria). $P$-values $<0.05$ were considered statistically significant.

A sample size estimation showed that 37 knees per group would be required to detect a clinically relevant difference of 1 point with a standard deviation of 1.5 points in the anterior knee pain VAS score, with an alpha of 0.05 and a power of $80 \%$.

\section{Results \\ Flowchart}

One hundred six participants were included for the study. Due to administrative protocol deviations, three patients from both groups were immediately excluded. Three additional patients of the MB group received wrong implant. Forty-seven patients in the $\mathrm{MB}$ and 50 patients in the FB group were available for the baseline data. Forty-two patients in the $\mathrm{MB}$ group and 48 patients in the FB group were available for the 5-year follow-up (Fig. 1). 


\section{$\checkmark \frac{\mathrm{CONSORT}}{\text { TRANSPARENT REPORTING of TRIALS }}$}

CONSORT 2010 Flow Diagram

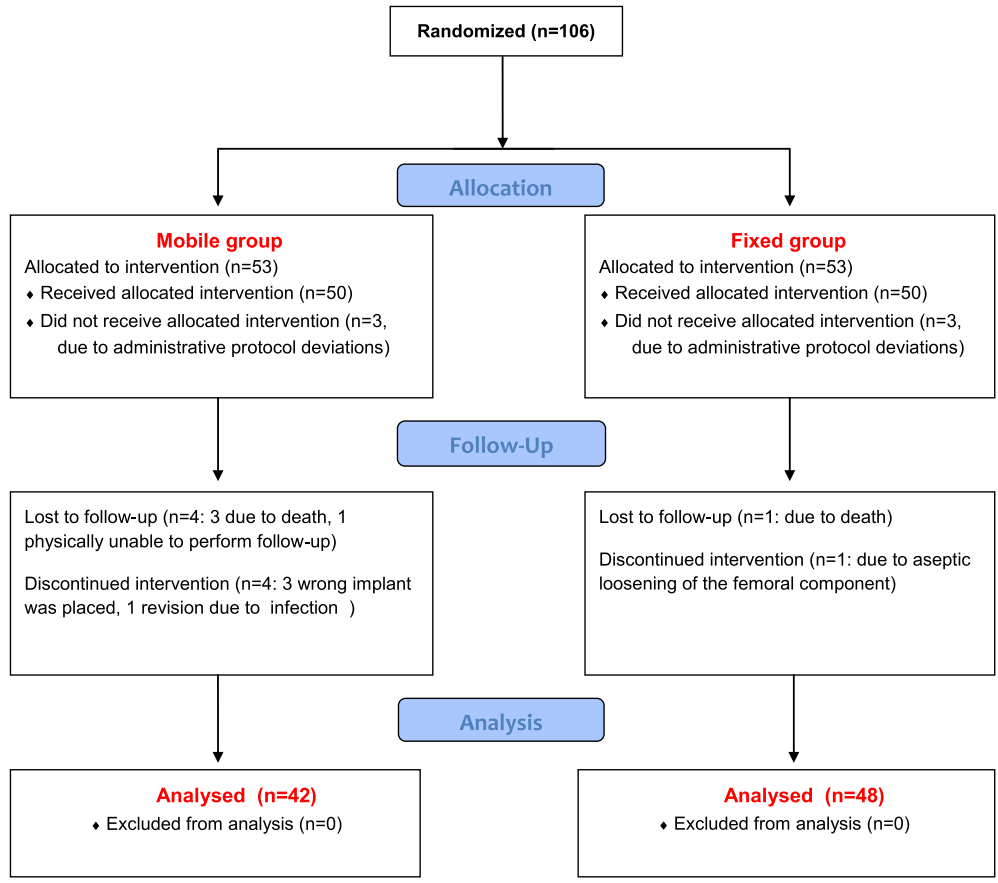

Fig. 1 Flow-chart of participants. One hundred six participants were included for the study. Due to administrative protocol deviations, three patients from both groups were immediately excluded. Three additional patients of the MB group received wrong implant. Forty-seven patients in the MB and 50 patients in the FB group were available for the baseline data. Forty-two patients in the MB group and 48 patients in the FB group were available for the 5-year follow-up

\section{Demographics}

There was no significant difference between the two surgical groups with respect to gender, age, BMI, side of operation or primary and secondary outcome measurements (Table 1).

\section{Primary outcomes}

At 5 years follow-up, median AKP scores during chair rise and during stair climb in the 'fixed' group were 0 (range 0-7) and 0 (range $0-8$ ), respectively. In the 'mobile' group median pain scores during chair rise and stair climb were both zero (range 0-7). No statistically significant difference in anterior knee pain during chair rise $(p=0.5)$ and anterior knee pain during stair climb $(p=0.8)$ between the two surgical groups was found (Table 2). There was no significant difference between groups in terms of percentage of participants having AKP during chair rise (FB group $22 \%$ vs. $\mathrm{MB}$ group $14.9 \%, p=0.3)$ or during stair climb (16\% vs. $17 \%$, respectively, $p=0.9$ ).

\section{Secondary outcomes}

The ability to climb stairs and to rise from a chair, ROM, KSS scores, RAND-36 scores and patellar tilt were not statistically different between the two surgical groups (Table 2).

There was no statistically significant difference between the $\mathrm{FB}$ and $\mathrm{MB}$ groups in terms of ability to rise from a chair ( $p=0.6,97.9 \%$ vs. $95.2 \%$, respectively) or ability to climb stairs ( $p=0.697 .9 \%$ vs. $97.9 \%$, respectively).

There was no statistically significant difference between the FB and MB groups in terms of median ROM $\left(p=0.9,110^{\circ}(70-130)\right.$ vs. $110^{\circ}(85-130)$, respectively).

There was no statistically significant difference between the FB and MB groups in terms of total KSS and RAND-36 (Table 2).

There was no statistically significant difference between the $\mathrm{FB}$ and $\mathrm{MB}$ groups in terms of patellar tilt at $30^{\circ}, 60^{\circ}, 90^{\circ}$ degrees of flexion $(p=0.4,2.56 \pm 3.62$ vs. $1.98 \pm 3.58, p=0.6,1.96 \pm 3.15$ vs. $1.80 \pm 3.82, p=0.4$, $1.81 \pm 3.25$ vs. $1.40 \pm 3.42$, respectively). 
Table 1 Baseline characteristics and pre-operative values of outcomes

\begin{tabular}{|c|c|c|}
\hline & $\begin{array}{l}\text { Fixed } \\
(n=50)\end{array}$ & $\begin{array}{l}\text { Mobile } \\
(n=47)\end{array}$ \\
\hline BMI $\left(\mathrm{kg} / \mathrm{m}^{2}\right)$ & $30.1( \pm 4.5)$ & $28.7( \pm 4.2)$ \\
\hline Side (L/R) & $22 / 28$ & $25 / 22$ \\
\hline AKP during chair rise (VAS 0-10 median) & $5(0-10)$ & $4(0-8)$ \\
\hline AKP during chair rise (yes/no \%) & $80 / 20$ & $85.1 / 14.9$ \\
\hline AKP during stair climb (VAS 0-10 median) & $5.5(0-10)$ & $5(0-9)$ \\
\hline AKP during stair climb (yes/no \%) & $90 / 10$ & $83 / 17$ \\
\hline Ability to rise from a chair (able/unable \%) & $72 / 28$ & $82.9 / 17.1$ \\
\hline Ability to climb stairs (able/unable\%) & $97.9 / 2.1$ & $95.3 / 4.7$ \\
\hline \multicolumn{3}{|l|}{ Range of motion (ROM) (degrees) } \\
\hline Flexion & $110(85-140)$ & $110(75-140)$ \\
\hline Extension & $-5(-20-5)$ & $-5(-35-5)$ \\
\hline Total & $105(70-140)$ & $110(65-140)$ \\
\hline \multicolumn{3}{|l|}{ KSS } \\
\hline Pain & $48(11-92)$ & $49(11-83)$ \\
\hline Function & $55(0-80)$ & $60(0-90)$ \\
\hline Total & $101(31-157)$ & $106(25-151)$ \\
\hline \multicolumn{3}{|l|}{ RAND-36 } \\
\hline Physical functioning & $30(5-75)$ & $35(5-90)$ \\
\hline Social role functioning & $62(0-100)$ & $62(0-100)$ \\
\hline Physical role functioning & $0(0-100)$ & $0(0-100)$ \\
\hline Emotional role functioning & $33(0-100)$ & $50(0-100)$ \\
\hline Mental health & $60(4-100)$ & $70(8-96)$ \\
\hline Vitality & $50(15-95)$ & $55(0-90)$ \\
\hline Bodily pain & $40(0-80)$ & $40(0-80)$ \\
\hline General health perceptions & $60(15-95)$ & $62.5(20-100)$ \\
\hline General health change & $50(0-75)$ & $50(0-100)$ \\
\hline \multicolumn{3}{|l|}{ Patellar tilt median (degrees) } \\
\hline 30 degrees flexion & $2(0-25)$ & $2(-1-13)$ \\
\hline 60 degrees flexion & $2(0-13)$ & $2(0-11)$ \\
\hline 90 degrees flexion & $1(0-11)$ & $2(0-10)$ \\
\hline \multicolumn{3}{|l|}{ Patella tilt mean (degrees + SD) } \\
\hline 30 degrees of flexion & $2.70 \pm 4.06$ & $3.0 \pm 3.39$ \\
\hline 60 degrees of flexion & $2.26 \pm 2.72$ & $2.72 \pm 2.73$ \\
\hline 90 degrees of flexion & $1.58 \pm 2.17$ & $2.29 \pm 2.51$ \\
\hline
\end{tabular}

\section{Discussion}

Compared to the FB-TKA patients, patients in the MBTKA group did not benefit from less anterior knee pain during rising from a chair or climbing stairs at 5 years follow-up in this study. This outcome is in line with the finding of previous meta-analyses, however AKP was not mentioned specifically. Only two meta-analyses [50, 74] reported lower pain scores in the $\mathrm{MB}$ group, but the quality of evidence was moderate to low [50, 74].
Table 2 Primary and secondary outcomes

\begin{tabular}{|c|c|c|c|}
\hline & $\begin{array}{l}\text { Fixed } \\
(n=48)\end{array}$ & $\begin{array}{l}\text { Mobile } \\
(n=42)\end{array}$ & $p$-value \\
\hline \multicolumn{4}{|l|}{ Primary outcomes } \\
\hline $\begin{array}{l}\text { AKP during chair rise } \\
\text { median (VAS 0-10) }\end{array}$ & $0(0-7)$ & $0(0-7)$ & 0.5 \\
\hline $\begin{array}{l}\text { AKP during chair rise } \\
\text { (yes/no \%) }\end{array}$ & $22 / 78$ & $14.9 / 85.1$ & 0.3 \\
\hline $\begin{array}{l}\text { AKP during stair climb } \\
\text { median (VAS 0-10) }\end{array}$ & $0(0-8)$ & $0(0-7)$ & 0.8 \\
\hline $\begin{array}{l}\text { AKP during stair climb } \\
\text { (yes/no \%) }\end{array}$ & $16 / 84$ & $17 / 83$ & 0.9 \\
\hline \multicolumn{4}{|l|}{ Secondary outcomes } \\
\hline $\begin{array}{l}\text { Ability to rise from chair } \\
\text { (able/unable \%) }\end{array}$ & $97.9 / 2.1$ & $95.2 / 4.8$ & $0.6^{*}$ \\
\hline $\begin{array}{l}\text { Ability to climb stairs } \\
\text { (able/unable\%) }\end{array}$ & $97.9 / 2.1$ & $97.9 / 4.8$ & $0.6^{*}$ \\
\hline \multicolumn{4}{|l|}{ Range of motion (ROM) (degrees) } \\
\hline Flexion & $110(80-130)$ & $110(85-130)$ & 0.9 \\
\hline Extension & $0(-10-5)$ & $-0(-10-5)$ & 0.7 \\
\hline Total & $110(70-130)$ & $110(85-130)$ & 0.9 \\
\hline \multicolumn{4}{|l|}{ KSS } \\
\hline Pain & $94.0(62-100)$ & $95(61-100)$ & 0.8 \\
\hline Function & $80(30-100)$ & $87.5(5-100)$ & 0.8 \\
\hline Total & $174.5(102-200)$ & $178.5(95-200)$ & 0.8 \\
\hline \multicolumn{4}{|l|}{ RAND-36 } \\
\hline Physical functioning & $55(5-100)$ & $55(0-100)$ & 0.6 \\
\hline Social role functioning & $75(25-100)$ & $75(0-100)$ & 0.7 \\
\hline Physical role functioning & $25(0-100)$ & $25(0-100)$ & 0.7 \\
\hline Emotional role functioning & $100(0-100)$ & $67(0-100)$ & 0.3 \\
\hline Mental health & $68(4-100)$ & $72(20-100)$ & 0.5 \\
\hline Vitality & $60(0-100)$ & $65(15-90)$ & 0.9 \\
\hline Bodily pain & $67(12-100)$ & $67(0-100)$ & 0.7 \\
\hline General health perceptions & $65(10-95)$ & $55(10-95)$ & 0.6 \\
\hline General health change & $50(25-75)$ & $50(0-100)$ & 0.6 \\
\hline \multicolumn{4}{|l|}{ Patellar tilt median (degrees) } \\
\hline 30 degrees flexion & $1(0-15)$ & $0.5(0-17)$ & 0.4 \\
\hline 60 degrees flexion & $0(0-15)$ & $0(0-20)$ & 0.6 \\
\hline 90 degrees flexion & $0(0-16)$ & $0(0-20)$ & 0.4 \\
\hline \multicolumn{4}{|l|}{ Patellar tilt mean (degrees + SD) } \\
\hline 30 degrees flexion & $2.56 \pm 3.62$ & $1.98 \pm 3.58$ & \\
\hline 60 degrees flexion & $1.96 \pm 3.15$ & $1.80 \pm 3.82$ & \\
\hline 90 degrees flexion & $1.81 \pm 3.25$ & $1.40 \pm 3.42$ & \\
\hline
\end{tabular}

*Fisher's Exact test

Price [75] and Breugem [76] reported lower pain scores in the $\mathrm{MB}$ group in the short term, but the same outcome was not confirmed in the long term [76, 77] nor did it differentiate AKP from general knee pain. The study by Biau [78] also showed a lower AKP in the MB group, 
however the difference was not statistically significant. This study showed $22 \%$ and $16 \%$ of patients had AKP during chair rise and stair climb in the FB group, meanwhile the AKP was $14.9 \%$ and $17 \%$ in the $\mathrm{MB}$ group during the same activities. Popovic [9] reported a much higher rate of AKP (49.2\%) in posterior stabilised MB-TKA. The outcome was explained with the suboptimal trochlear design of the type of prosthesis. Wyatt et al. [57] reported a significantly higher rate of revision for secondary resurfacing of the patella in FB-PS-TKA designs compared with MBTKA, which is not in line with the result of this study, however Wyatt reported a retrospective study.

AKP is known to cause the most problems in daily activities such as rising from a chair, or climbing stairs. Theoretically a larger percentage of patients who received MB-TKA would be able to rise from a chair and climb stairs compared with patients from the FB-TKA group, and while less patellar compression pain was expected in the MB group, it could not be confirmed. Little evidence can be found in the literature in terms of the ability to rise from a chair or climb stairs. Pais-Brito [79] found no differences between the MB- and FB-TKA groups in the ability to ascend and descend stairs. Woolson [80] stated that more patients in the MB group required aid to climb stairs compared with patients in the FB group, however this finding was statistically not significant. The meta-analysis by Smith [81] found no significant difference between groups based on nine studies.

Theoretically the MB design could lead to better ROM during daily activities [82]. We observed no difference in ROM between patients in either group. Most metaanalyses [42, 47, 48, 50, 81] also reported no significant differences between groups. Carothers [83] found no difference in $\mathrm{ROM}$ between groups, but the $\mathrm{MB}$ groups were significantly better in increase of ROM compared with the pre-operative function. Aglietti [84] found better ROM in the MB group while Haas [82] reported better $\mathrm{ROM}$ in the FB group. Kim [85] found minimally better ROM in the MB group although the difference was not statistically significant. The variation in design of the MB produced differences in ROM between the MB- and FB-TKA [49]. Since several MB designs are available (pure rotation, pure translation, combined rotation-translation and meniscal bearing) the results of meta-analyses can be influenced. A MB insert stops moving at flexion deeper than $90^{\circ}$ and after this point the MB prostheses performs essentially as a fixed-bearing implant [49]. The question is how mobile is the bearing in $\mathrm{MB}$ prosthesis design during the stance phase of stair climbing and during rising from a chair if the flexion of the knee is less than $90^{\circ}$ ? The mobile-bearing insert can act as a fixed-bearing, but it is not proven. Studies utilising fluoroscopic techniques have demonstrated that knee joint kinematics are highly unpredictable in $\mathrm{MB}$ prostheses
[86]. If mobile bearing insert act as a fixed bearing it could be an explanation why no differences were found between the two type of prostheses.

Stryker Scorpio PS MB and FB design was used in this study. The femoral components are the same in both prostheses with slightly different inserts. Both knees have single radius design and according to the manufacturer the Scorpio PS has great internal and external rotational freedom throughout the full range of motion. The design is not conforming between femoral component and tibial insert and as far as the authors know, there is no difference in conformity between the $\mathrm{MB}$ and $\mathrm{FB}$ design.

Most studies and meta-analyses [42, 47-50, 81, 83, 87, 88] reported no significant differences in clinical scores (KSS, HSS, WOMAC, OKS) between the MB and FB design TKA. Only two studies found significant differences in KSS is favour of the MB design TKA. The meta-analysis by van der Voort [49] reported significantly better physical SF-12 scores. The RAND-36 in our study was not different between groups.

No significant differences between the MB- and FBTKAs were found in terms of mean and median patellar tilt in this study, which corresponds to Heinert's results in a cadaveric study [89]. The rate of lateral releases was reported by Ferguson [90]. Lateral release was performed when tilting or subluxation was observed using the "no thumb" technique. The rate of releases was equal between the $\mathrm{MB}$ and $\mathrm{FB}$ groups. In contrast significantly smaller intra-operative lateral tilts of the patella were reported by Sawaguchi [55]. The average maximum contact stress of the patella was also significantly smaller. Skwara et al. [56] performed in vitro measurements of the patella. The MB design TKA showed evidently lower patellofemoral contact stresses than the FB design. Recent meta-analyses [42, 81, 88] reported no significant differences in lateral tilt of the patella between the MB and FB design TKA.

\section{Conclusion}

No statistically significant difference was found between the FB and MB design PS-TKA in terms of patellofemoral pain and function at 5 years follow-up in this study.

\section{Limitation of the study}

There are a few limitations to the study. There was no postoperative analysis on CT scan for the rotational position of the femoral component since it has a great influence on the patellar tilt. The authors also see a ceiling effect in the scoring lists and the question is whether they are sensitive enough to arrive at conclusions.

\section{Abbreviations}

AKP: Anterior knee pain; CRPS: Complex regional pain syndrome; CT: Computer tomography; FB: Fixed-bearing; FU: Follow-up; KSS: Knee society score; MB: Mobile-bearing; PS: Posterior stabilized; RAND-36: Research 
and development survey; ROM: Range of motion; SPSS (software): Statistical package for the social sciences; TEA: Transepicondylar line; TKA: total knee arthroplasty; VAS: Visual analogue scale; WOMAC: Western Ontario and McMaster Universities Arthritis Index

\section{Acknowledgements}

Not applicable.

\section{Funding}

All costs of the study which takes part of the Dutch standard medical care (admission, operation, standard follow-up, implant) was covered by the insurance of the participants. All costs of this study which does not belong to the Dutch standard medical care was financially supported by Stryker Corporation. Three hundred fifty euro per patient was paid for not standard, study related follow-up (3 months, 2 years, 5 years) and radiological examinations (5 times patella series). Three hundred thirty euro per patient was paid database management, administrative support, registration costs and statistical analyses. The study was initiated through the surgeons. During the period of the study Stryker was the supplier of hip and knee implants. All study data belong to Maasticht University Medical Centre. The statistics and the article was made without the influence of the sponsor

\section{Availability of data and materials}

The datasets generated and analysed during the current study available from the corresponding author on reasonable request.

\section{Authors' contribution}

FPZ collected data, wrote and submitted the paper. JLM participated in the design of the study and coordinated the study. vSMJ initiated the study, participated in the design of the study and performed the operations. DP participated in the design of the study, performed the operations and revised the manuscript. EPJ helped in the interpretation of the data and revised the manuscript. AJJ initiated the study, participated in the design of the study. All authors read and approved the final manuscript.

\section{Ethics approval and consent to participate}

Registration Number: ClinicalTrials.gov NCT02892838.

Ethical approval was obtained from the Medisch-ethische toetsingscommissie azM/UM (ethics committee azM/UM) (Nr: METC 08-055), as part of the research program, "Should my knee rotate? A randomised controlled trial to compare fixed and mobile-bearing total knee arthroplasty using the Scorpio PS SuperFlex and Scorpio + PS Mobile Bearing knee systems".

A written informed consent was obtained from all participants.

\section{Consent for publication}

Not applicable: the manuscript does not contain any form of person's data.

\section{Competing interests}

All authors declare that they have no competing interests.

\section{Publisher's Note}

Springer Nature remains neutral with regard to jurisdictional claims in published maps and institutional affiliations.

\section{Author details}

'Department of Orthopaedic Surgery, CAPHRI Research School, Maastricht University Medical Centre, P. Debyelaan 25, 6229 HX Maastricht, the Netherlands. ${ }^{2}$ Reynaert Private Hospital, Maastricht, the Netherlands. ${ }^{3}$ Department of Orthopaedic Surgery, Zuyderland Hospital, Heerlen, the Netherlands.

Received: 16 October 2016 Accepted: 19 June 2017

Published online: 29 June 2017

\section{References}

1. Font-Rodriguez DE, Scuderi GR, Insall JN. Survivorship of cemented total knee arthroplasty. Clin Orthop Relat Res. 1997;345:79-86.

2. Callaghan JJ, O'Rourke MR, lossi MF, Liu SS, Goetz DD, Vittetoe DA, Sullivan PM, Johnston RC. Cemented rotating-platform total knee replacement. A concise follow up, at a minimum of fifteen years, of a previous report. J Bone Joint Surg Am. 2005;87(9):1995-8.
3. Keating EM, Meding JB, Faris PM, Ritter MA. Long-term followup of nonmodular total knee replacements. Clin Orthop Relat Res. 2002:404:34-9.

4. Gill GS, Joshi AB. Long-term results of cemented, posterior cruciate ligament-retaining total knee arthroplasty in osteoarthritis. Am J Knee Surg. 2001;14(4):209-14

5. Pavone $\mathrm{V}$, Boettner F, Fickert S, Sculco TP. Total condylar knee arthroplasty: a long-term follow-up. Clin Orthop Relat Res. 2001;388:18-25.

6. Ritter MA, Faris PM, Keating EM, Meding JB. Postoperative alignment of total knee replacement. Its effect on survival. Clin Orthop Relat Res. 1994;299:153-6.

7. Rodriguez JA, Bhende H, Ranawat CS. Total condylar knee replacement: a 20-year follow-up study. Clin Orthop Relat Res. 2001;388:10-7.

8. Shan L, Shan B, Suzuki A, Nouh F, Saxena A. Intermediate and long-term quality of life after total knee replacement: a systematic review and meta-analysis. J Bone Joint Surg Am. 2015;97(2):156-68.

9. Popovic N, Lemaire R. Anterior knee pain with posterior-stabilized mobile-bearing knee prosthesis: the effect of femoral component design. J Arthroplast. 2003;18:396-400.

10. Waters TS, Bentley G. Patellar resurfacing in total knee arthroplasty: a prospective, randomized study. J Bone Joint Surg Am. 2003:85-A:212-7.

11. Breugem SJ, Sierevelt IN, Schafroth MU, Blankevoort L, Schaap GR, van Dijk CN. Less anterior knee pain with mobile-beraring prosthesis compared with fixed bearing prosthesis. Clin Orthop Relat Res. 2008;466(8):1959-65.

12. Petersen W, Rembitzki IV, Brüggemann GP, Ellermann A, Best R, Koppenburg AG Liebau C. Anterior knee pain after total knee arthroplasty: a narrative review. Int Orthop. 2014;38(2):319-28.

13. Shervin D, Pratt K, Healey T, Nguyen S, Mihalko WM, El-Othmani MM, Saleh KJ. Anterior knee pain following primary total knee arthroplasty. World J Orthop. 2015;6(10):795-803.

14. Singh JA, Gabriel S, Lewallen D. The impact of gender, age and preoperative pain severity on pain after TKA. Clin Orthop Relat Res. 2008;466(11):2717-23.

15. Lavernia CJ, Alcerro JC, Contreras JS, Rossi MD. Ethnic and racial factors influencing well-being, perceived pain and physical function after primary joint arthroplasty. Clin Orthop Relat Res. 2011 Jul;469(7):1838-45.

16. Bonnin MP, Basiglini L, Archbold HA. What are the factors of residual pain after uncomplicated TKA? Knee Surg Sports Traumatol Arthrosc. 2011;19(9):1411-7.

17. Liu SS, Buvanendran A, Rathmell JP, Sawhney M, Bae JJ, Moric M, et al. Predictors of moderate to severe acute postoperative pain after total hip and knee replacement. Int Orthop. 2012;36(11):2261-7.

18. Forsythe ME, Dunbar MJ, Hennigar AW, Sullivan MJ, Gross M. Prospective relation between catastrophizing and residual pain following knee arthroplasty: two-year follow-up. Pain Res Manag. 2008;13(4):335-41.

19. Brander VA, Stulberg SD, Adams AD, Harden RN, Bruehl S, Stanos SP, Houle T. Predicting total kne replacement pain a prospective, observational study. Clin Orthop Relat Res. 2003;416:27-36.

20. van Jonbergen HP, Reuver JM, Mutsaerts EL, Poolman RW. Determinants of anterior knee pain following total knee replacement: a systematic review. Knee Surg Sports Traumatol Arthrosc. 2014;22(3):478-99.

21. Dajani KA, Stuart MJ, Dahm DL, Levy BA. Arthroscopic treatment of patellar clunk and synovial hyperplasia after total knee arthroplasty. J Arthroplast. 2010;25(1):97-103.

22. Maloney WJ, Schmidt R, Sculco TP. Femoral component design and patellar clunk syndrome. Clin Orthop Relat Res. 2003;410:199-202.

23. Fukunaga K, Kobayashi A, Minoda Y, Iwaki H, Hashimoto Y, Takaoka K. The incidence of the patellar clunk syndrome in a recently designed mobile-bearing posteriorly stabilised total knee replacement. J Bone Joint Surg Br. 2009;91(4):463-8.

24. Rodríguez-Merchán EC, Gómez-Cardero P. The outerbridge classification predicts the need for patellar resurfacing in TKA. Clin Orthop Relat Res. 2010;468(5):1254-7.

25. Banks SA, Harman MK, Hodge WA. Mechanism of anterior impingement damage in total knee arthroplasty. J Bone Joint Surg Am. 2002;84-A(Suppl 2):37-42.

26. Bonnin MP, Schmidt A, Basiglini L, Bossard N, Dantony E. Mediolateral oversizing influences pain, function and flexion after TKA. Knee Surg Sports Traumatol Arthrosc. 2013;21(10):2314-24.

27. Bellemans J, Carpentier K, Vandenneucker H, Vanlauwe J, Victor J. The John Insall award: both morphotype and gender influence the shape of the knee in patients undergoing TKA. Clin Orthop Relat Res. 2010;468(1):29-36.

28. Mahfouz M, Abdel Fatah EE, Bowers LS, Scuderi G. Three-dimensional morphology of the knee reveals ethnic differences. Clin Orthop Relat Res. 2012;470(1):172-85. 
29. Hamilton DF, Burnett R, Patton JT, Howie CR, Moran M, Simpson AHRW, Gaston P. Implant design influences patient outcome after total knee arthroplasty. Bone Joint J. 2015;97-B(1):64-70.

30. van Jonbergen HP, Scholtes VA, Poolman RW. A randomised, controlled trial of circumpatellar electrocautery in total knee replacement without patellar resurfacing: a concise follow-up at a mean of 3.7 years. Bone Joint J. 2014;96-B(4):473-8

31. Cheng T, Zhu C, Guo Y, Shi S, Chen D, Zhang X. Patellar denervation with electrocautery in total knee arthroplasty without patellar resurfacing: a meta-analysis. Knee Surg Sports Traumatol Arthrosc. 2014;22(11):2648-54.

32. Meneghini RM. Should the patella be resurfaced in primary total knee arthroplasty? An evidence-based analysis. J Arthroplast. 2008;23(7 Suppl):11-4.

33. Li S, Chen Y, Su W, Zhao J, He S, Luo X. Systematic review of patellar resurfacing in total knee arthroplasty. Int Orthop. 2011;35(3):305-16.

34. Pilling RW, Moulder E, Allgar V, Messner J, Sun Z, Mohsen A. Patellar resurfacing in primary total knee replacement: a meta-analysis. J Bone Joint Surg Am. 2012;94(24):2270-8

35. Heegaard JH, Leyvraz PF, Hovey CB. A computer model to simulate patellar biomechanics following total knee replacement: the effects of femoral component alignment. Clin Biomech (Bristol, Avon). 2001;16(5):415-23.

36. Lee TQ, Morris G, Csintalan RP. The influence of tibial and femoral rotation on patellofemoral contact area and pressure. J Orthop Sports Phys Ther. 2003;33(11):686-93.

37. Hsu HC, Luo ZP, Rand JA, An KN. Influence of patellar thickness on patellar tracking and patellofemoral contact characteristics after total knee arthroplasty. J Arthroplast. 1996;11(1):69-80.

38. Berger RA, Crossett LS, Jacobs JJ, Rubash HE. Malrotation causing patellofemoral complications after total knee arthroplasty. Clin Orthop Relat Res. 1998:356:144-53.

39. Merican AM, Ghosh KM, Iranpour F, Deehan DJ, Amis AA. The effect of femoral component rotation on the kinematics of the tibiofemoral and patellofemoral joints after total knee arthroplasty. Knee Surg Sports Traumatol Arthrosc. 2011;19(9):1479-87.

40. Miller MC, Berger RA, Petrella AJ, Karmas A, Rubash HE. Optimizing femoral component rotation in total knee arthroplasty. Clin Orthop Relat Res. 2001;392:38-45.

41. Vertullo CJ, Easley ME, Scott WN, Insall JN. Mobile bearings in primary knee arthroplasty. J Am Acad Orthop Surg. 2001;9(6):355-64.

42. Bo ZD, Liao L, Zhao JM, Wei QJ, Ding XF, Yang B. Mobile bearing or fixed bearing? A meta-analysis of outcomes comparing mobile bearing and fixed bearing bilateral total knee replacements. Knee. 2014;21(2):374-81.

43. O'Connor JJ, Goodfellow JW. Theory and practice of meniscal knee replacement: designing against wear. Proc Inst Mech Eng H. 1996;210(3):217-22.

44. Menchetti PP, Walker PS. Mechanical evaluation of mobile bearing knees. Am J Knee Surg. 1997;10(2):73-81.

45. Callaghan JJ, Insall JN, Greenwald AS, Dennis DA, Komistek RD, Murray DW, Bourne RB, Rorabeck CH, Dorr LD. Mobile-bearing knee replacement: concepts and results. Instr Course Lect. 2001;50:431-49.

46. D'Lima DD, Trice M, Urquhart AG, Colwell CW Jr. Comparison between the kinematics of fixed and rotating bearing knee prostheses. Clin Orthop Relat Res. 2000;380:151-7.

47. Hofstede SN, Nouta KA, Jacobs W, van Hooff ML, Wymenga AB, Pijls BG, Nelissen RG, Marangvan de Mheen PJ. Mobile bearing vs fixed bearing prostheses for posterior cruciate retaining total knee arthroplasty for postoperative functional status in patients with osteoarthritis and rheumatoid arthritis. Cochrane Database Syst Rev. 2015;(2):CD003130.

48. Moskal JT, Capps SG. Rotating-platform TKA no different from fixed-bearing TKA regarding survivorship or performance: a meta-analysis. Clin Orthop Relat Res. 2014;472(7):2185-93.

49. van der Voort P, Pijls BG, Nouta KA, Valstar ER, Jacobs WC, Nelissen RG. A systematic review and meta-regression of mobile-bearing versus fixed-bearing total knee replacement in 41 studies. Bone Joint J. 2013;95-B(9):1209-16.

50. Li YL, Wu Q, Ning GZ, Feng SQ, Wu QL, Li Y, Hao Y. No difference in clinical outcome between fixed- and mobile-bearing TKA: a meta-analysis. Knee Surg Sports Traumatol Arthrosc. 2014;22(3):565-75.

51. Capella M, Dolfin M, Saccia F. Mobile bearing and fixed bearing total knee arthroplasty. Ann Transl Med. 2016;4(7):127.

52. Buechel FF, Pappas MJ. New Jersey low contact stress knee replacement system. Ten-year evaluation of meniscal bearings. Orthop Clin North Am. 1989;20(2):147-77
53. Stiehl JB, Dennis DA, Komistek RD, Keblish PA. In vivo kinematic comparison of posterior cruciate ligament retention or sacrifice with a mobile bearing total knee arthroplasty. Am J Knee Surg. 2000;13(1):13-8.

54. Colwell CW Jr, Chen PC, D'Lima D. Extensor malalignment arising from femoral component malrotation in knee arthroplasty: effect of rotating-bearing. Clin Biomech (Bristol, Avon). 2011;26(1):52-7.

55. Sawaguchi N, Majima T, Ishigaki T, Mori N, Terashima T, Minami A. Mobile-bearing total knee arthroplasty improves patellar tracking and patellofemoral contact stress: in vivo measurements in the same patients. J Arthroplast. 2010;25(6):920-5.

56. Skwara A, Tibesku CO, Ostermeier S, Stukenborg-Colsman C, Fuchs-Winkelmann S. Differences in patellofemoral contact stresses between mobile-bearing and fixed-bearing total knee arthroplasties: a dynamic in vitro measurement. Arch Orthop Trauma Surg. 2009;129(7):901-7.

57. Wyatt MC, Frampton C, Horne JG, Devane P. Mobile- versus fixed-bearing modern total knee replacements- which is the more patella-friendly design?: the 11-year New Zealand joint registry study. Bone Joint Res. 2013;2(7):129-31.

58. Matsuda $Y$, Ishii $Y$, Noguchi $H$, Ishii R. Varus-valgus balance and range of movement after total knee arthroplasty. J Bone Joint Surg (Br). 2005;87-B:804-8.

59. Eisenhuth SA, Saleh KJ, Cui Q, Clark CR, Brown TE. Patellofemoral instability after total knee arthroplasty. Clin Orthop Relat Res. 2006;446:149-60.

60. Middleton FR, Palmer SH. How accurate is Whiteside's line as a reference axis in total knee arthroplasty? Knee. 2007;14(3):204-7.

61. Lützner J, Krummenauer F, Günther KP, Kirschner S. Rotational alignment of the tibial component in total knee arthroplasty is better at the medial third of tibial tuberosity than at the medial border. BMC Musculoskelet Disord. 2010;11:57.

62. Steinbrück A, Schröder C, Woiczinski M, Müller T, Müller PE, Jansson V, Fottner A. Influence of tibial rotation in total knee arthroplasty on knee kinematics and retropatellar pressure: an in vitro study. Knee Surg Sports Traumatol Arthrosc. 2016;24(8):2395-401.

63. Asano $\mathrm{H}$, Hoshino A, Wilton TJ. Soft-tissue tension total knee arthroplasty. J Arthroplast. 2004;19(5):558-61.

64. Streiner DL, Norman GR. Chapter 4: scaling responses, in health measurement. Oxford: Oxford University Press; 1995. p. 32.

65. Nies F de, Fidler MW. Visual analog scale for the assessment of total hip arthroplasty. J Arthroplast 1997;12(4):416-419.

66. Jones SE, Kon SS, Canavan JL, Patel MS, Clark AL, Nolan CM, Polkey MI, Man WD. The five-repetition sit-to-stand test as a functional outcome measure in COPD. Thorax. 2013;68(11):1015-20.

67. Norkin CC, White DJ. Measurement of joint motion; a guide to goniometry. F.A. Davis Company; Philadelphia. 4 edition 2009. ISBN 0803665792.

68. Brosseau L, Tousignant M, Budd J, Chartier N, Duciaume L, Plamondon S, O'Sullivan JP, O'Donoghue S, Balmer S. Intratester and intertester reliability and criterion validity of the parallelogram and universal goniometers for active knee flexion in healthy subjects. Physiother Res Int. 1997;2(3):150-66.

69. Lenssen AF, van Dam EM, Crijns YH, Verhey M, Geesink RJ, van den Brandt PA, de Bie RA. Reproducibility of goniometric measurement of the knee in the in-hospital phase following total knee arthroplasty. BMC Musculoskelet Disord. 2007:8:83.

70. Insall JN, Dorr LD, Scott RD, Scott WN. Rationale of the knee society clinical rating system. Clin Orthop Relat Res. 1989;248:13-4.

71. Hays RD, Sherbourne CD, Mazel RM, The RAND. 36-item health survey 1.0. Health Econ. 1993;2(3):217-27.

72. Hays RD, Morales LS. The RAND-36 measure of health-related quality of life. Ann Med. 2001 Jul;33(5):350-7.

73. Ewald FC. The knee society total knee arthroplasty roentgenographic evaluation and scoring system. Clin Orthop Relat Res. 1989;248:9-12.

74. Jacobs W, Anderson P, Limbeek J, Wymenga A. Mobile bearing vs fixed bearing prostheses for total knee arthroplasty for post-operative functional status in patients with osteoarthritis and rheumatoid arthritis. Cochrane Database Syst Rev. 2004;2:CD003130.

75. Price AJ, Rees JL, Beard D, Juszczak E, Carter $S$, White $S$, de Steiger $R$, Dodd CA, Gibbons M, McLardy-Smith P, Goodfellow JW, Murray DW. A mobile-bearing total knee prosthesis compared with a fixed-bearing prosthesis. A multicentre single-blind randomised controlled trial. J Bone Joint Surg Br. 2003;85(1):62-7.

76. Breugem SJ, van Ooij B, Haverkamp D, Sierevelt IN, van Dijk CN. No difference in anterior knee pain between a fixed and a mobile posterior stabilized total knee arthroplasty after 7.9 years. Knee Surg Sports Traumatol Arthrosc. 2014;22(3):509-16. 
77. Beard DJ, Pandit H, Price AJ, Butler-Manuel PA, Dodd CA, Murray DW, Goodfellow JW. Introduction of a new mobile-bearing total knee prosthesis: minimum three year follow-up of an RCT comparing it with a fixed-bearing device. Knee. 2007:14(6):448-51.

78. Biau D, Mullins MM, Judet T, Piriou P. Mobile versus fixed-bearing total knee arthroplasty: mid-term comparative clinical results of 216 prostheses. Knee Surg Sports Traumatol Arthrosc. 2006;14(10):927-33.

79. Pais-Brito JL, Rafols-Urquiza B, Gonzalez-Massieu L, Herrera-Perez M, Aciego-De Mendoza M, De Bergua Domingo J. Reduced patellofemoral and walking pain with mobile-bearing vs. fixed-bearing total knee replacements: a mid-term prospective analytic study. Acta Orthop Traumatol Turc. 2015;49(4):375-81.

80. Woolson ST, Northrop GD. Mobile- vs. fixed-bearing total knee arthroplasty: a clinical and radiologic study. J Arthroplast. 2004;19(2):135-40.

81. Smith H, Jan M, Mahomed NN, Davey JR, Gandhi R. Meta-analysis and systematic review of clinical outcomes comparing mobile bearing and fixed bearing total knee arthroplasty. J Arthroplast. 2011;26(8):1205-13.

82. Haas B, Dennis DA, Komistek RD, Brumley JT 2nd, Hammill C. Range of motion of posterior-cruciate-substituting total knee replacements: the effect of bearing mobility. J Bone Joint Surg Am. 2001;83-A Suppl 2(Pt 1):51-5.

83. Carothers JT, Kim RH, Dennis DA, Southworth C. Mobile-bearing total knee arthroplasty: a meta-analysis. J Arthroplast. 2011;26(4):537-42.

84. Aglietti P, Baldini A, Buzzi R, Lup D, De Luca L. Comparison of mobilebearing and fixed-bearing total knee arthroplasty: a prospective randomized study. J Arthroplasty. 2005;20(2):145-53.

85. Kim YH, Kim JS, Choe JW, Kim HJ. Long-term comparison of fixed-bearing and mobile-bearing total knee replacements in patients younger than fifty-one years of age with osteoarthritis. J Bone Joint Surg Am. 2012;94(10):866-73.

86. Stiehl JB, Dennis DA, Komistek RD, Keblish PA. In vivo kinematics analysis of a mobile bearing total knee prosthesis. Clin Orthop Rel Res. 1997;345:60-6.

87. Hopley CD, Crossett LS, Chen AF. Long-term clinical outcomes and survivorship after total knee arthroplasty using a rotating platform knee prosthesis: a meta-analysis. J Arthroplast. 2013;28(1):68-77.

88. Wen Y, Liu D, Huang Y, Li B. A meta-analysis of the fixed-bearing and mobile-bearing prostheses in total knee arthroplasty. Arch Orthop Trauma Surg. 2011;131(10):1341-50.

89. Heinert G, Kendoff D, Preiss S, Gehrke T, Sussmann P. Patellofemoral kinematics in mobile-bearing and fixed-bearing posterior stabilised total knee replacements: a cadaveric study. Knee Surg Sports Traumatol Arthrosc. 2011;19(6):967-72.

90. Ferguson KB, Bailey O, Anthony I, Stother IG, Blyth MJ. A comparison of lateral release rates on fixed- versus mobile-bearing total knee arthroplasty. J Orthop Traumatol. 2015;16(2):87-90.

\section{Submit your next manuscript to BioMed Central and we will help you at every step:}

- We accept pre-submission inquiries

- Our selector tool helps you to find the most relevant journal

- We provide round the clock customer support

- Convenient online submission

- Thorough peer review

- Inclusion in PubMed and all major indexing services

- Maximum visibility for your research

Submit your manuscript at www.biomedcentral.com/submit

C) Biomed Central 